\title{
sciendo ANALYSIS OF CORNERS MILLING OF ALUMINUM ALLOY ELEMENTS
}

doi:10.2478/mape-2018-0005

Date of submission of the article to the Editor: 03/2018

Date of acceptance of the article by the Editor: 07/2018
MAPE 2018, volume 1, issue 1, pp. 33-39

\author{
MSc., Eng. Kamil Anasiewicz \\ PhD., Eng. Maciej Włodarczyk \\ Lublin University of Technology, Poland
}

\begin{abstract}
The article presents comparative research on the effects of milling of concave corners of elements made of aluminum alloy 7075. The work focuses on the study of the impact of changes in technological parameters and types of machining on the obtained geometrical state of the machined samples. Correct milling of the corners requires selection of the appropriate feed rate and the proper engagement angle of the milling cutter. At the corners, tool engagement angle increases, which significantly hinders the execution of stable machining and adversely affects the geometric and qualitative characteristics of the surface in the corners. Study with application of various strategies and technological parameters of milling corners with variable opening angles were carried out. The main parameters of surface roughness of the machined elements were examined. When analyzing the results obtained, conclusions were formulated indicating the relationship between the change of selected technological parameters, with the assumed type of treatment, and the obtained quality parameters of the samples made.
\end{abstract}

Keywords: aluminum machining, surface roughness, machining strategy

\section{INTRODUCTION}

The production of modern constructions is oriented towards decreasing their mass while maintaining appropriate strength properties. To meet these expectations, aluminum alloys are often used for this purpose. They have much lower density compared to the steel while maintaining a similar value of relative strength. In addition, they are characterized by high corrosion resistance and increased impact strength in low temperatures, which is of great importance in the aviation industry (Oczoś and Kawalec, 2012). The current technological advancement of machines used in the machining of metals allows to cut workpieces in several axes simultaneously, making it possible to obtain parts with complex geometry and high manufacturing precision (Burek and Płodzień, 2012; Pieśko, 2014).

Concave corner milling requires the selection of a suitable feed rate and the proper engagement angle of milling cutter. As tool moves towards the inner corners, the engagement angle of the tool increases, making it difficult to perform stable machining. Variable cutting forces may cause vibrations of the tool, and thus the deterioration of the surface quality of the workpiece. There is also the possibility of undercutting corners, chipping the cutting edge or completely damaging the tool (Wei et al., 2010). One of the methods of preventing this phenomenon is the strategy of reducing the feed per tooth in the corner zones (Jemielniak, 2004; Kłonica et al., 2015; Yue et al., 2018). Method involves reducing the feed value just before the corner, maintaining the reduced parameter during milling the corner, then again increasing the feed rate after leaving the corner. For a smoother transition of machining speed, the change of feed values can be divided into several stages (Fig. 1a) (Choy and Chan, 2002; Tsui and Chan, 2005).

Another method of solving the problem of concave corner milling is the trochoidal machining strategy. The name of the strategy comes from the shape received by the tool path. It can be 
determined as a circular milling with the progressive movement of the tool advancing forward (Fig. 1 b). This method is mainly used for milling grooves, cavities and closed pockets. It allows the removal of a large amount of material with a single tool passage, while reducing the tool engagement angle, which translates into a reduction in cutting forces, while allowing to increase the depth of cut $\left(a_{p}\right)$, for a small cutting width $\left(a_{e}\right)$. By using a greater part of length of cut (LOC) of the tool, machining has a positive effect on its durability. The use of trochoidal machining allows for a smooth change of direction and values of cutting forces, which is important in high speed machining [Burek and Płodzień, 2012; Kłonica et al., 2015, Pieśko and Zagórski, 2011) .
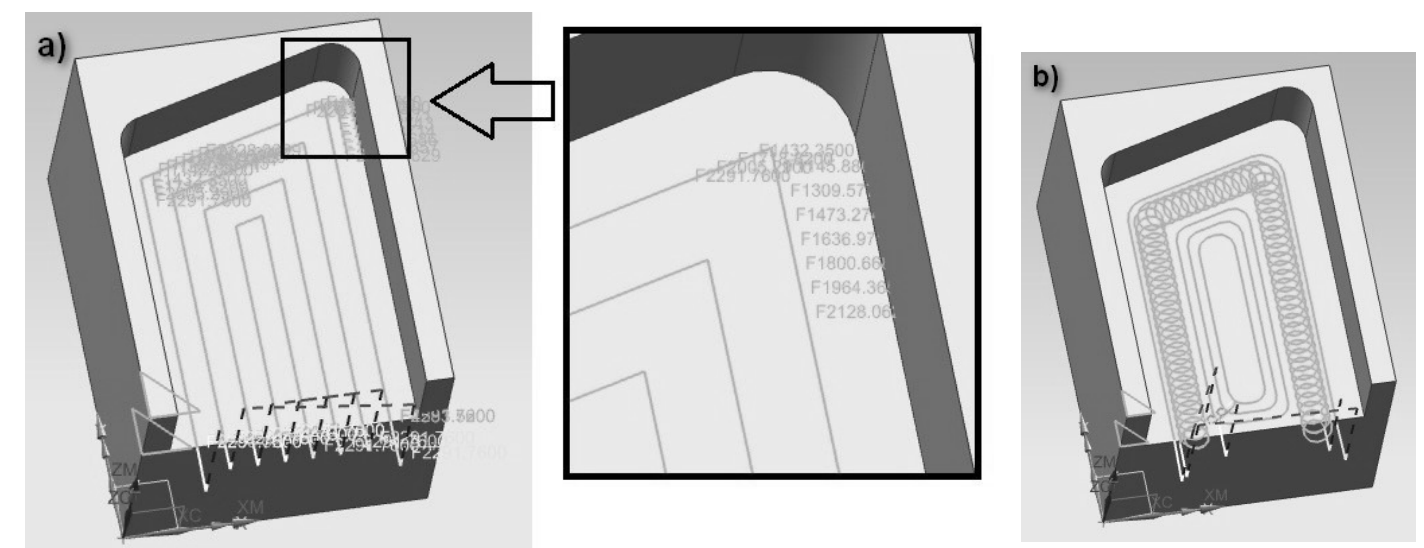

Fig. 1. a) View of paths with the indicated values of reduced feed rate in the corner; b) view of tool paths in trochoidal machining

The problem of the increased tool engagement angle in the concave corners can be solved by using several operations to manufacture the element. The first operation will be roughing. Its task is to remove most of the material, while leaving the pre-determined allowance for subsequent operations. Then, a small layer of material is removed to equalize the surface after roughing operation. Finally, in the finishing milling the remaining layer of the material allowance is removed, which avoids problems with excess material in the corners and allows achieving predetermined surface quality (Burek and Płodzień, 2012, Tsui and Chan, 2005).

The article focuses on the study of the impact of changes in technological parameters and types of processing on the obtained geometric state of the samples manufactured. The main surface roughness parameters of the elements were examined.

\section{METHODOLOGY OF RESEARCH}

The main goal of the study presented in the paper was to assess the impact of technological parameters on selected quality and quantity indicators allowing to evaluate the quality of the surface of the milled corner. In order to obtain this information, tests were carried out on a 3axis vertical machining center on samples made of aluminum alloy 7075 (Fig. 2), using various technological parameters and types of machining.

For the proper recognition of individual samples, a system of markings was created enabling their easy identification later. Research included five angle values of the corners of $60^{\circ}, 75^{\circ}$, $90^{\circ}, 105^{\circ}$ and $120^{\circ}$. The range of angular values tested was determined due to the ability to check the behavior of the tool with the change of the engagement angle of the tool in the corner. Each angle value was tested in 3 types of machining, i.e.: roughing, semi-finishing and finishing. 


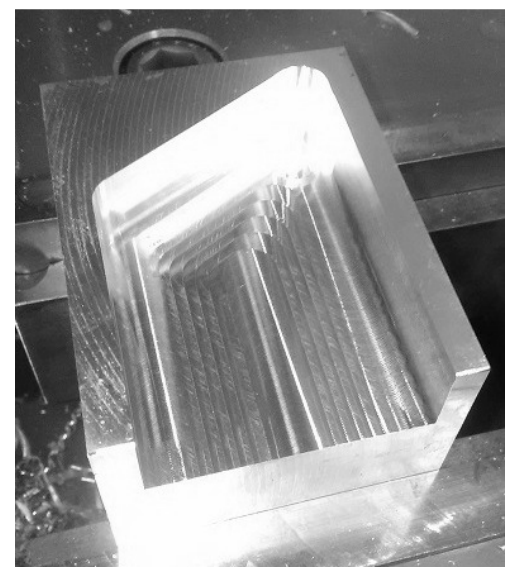

Fig. 2. A sample of the material under investigation after the milling operation

In addition, each type of machining was tested at a constant feed per tooth rate at the corners as well as with the feed deceleration in their area. It gives 6 measurements for each corner angle value. The description of the individual sample consisted of information for which value of the angle the test was carried out, with what type of treatment and if the deceleration in the corners was used. For example, a sample named "60-120 SF" means the $60^{\circ}$ and $120^{\circ}$ angle values processed with semi - finishing. The sample "60-120 SF SDC" means the tested values of the same angles processed with semi-finished machining with feed deceleration in the corners. After the tests on the CNC machine, the samples were tested with a profilometer to determine the surface roughness of the machined corners.

The tests were performed with a WNT solid carbide cutter No. 53518100. Tool with diameter of $\varnothing=10 \mathrm{~mm}, 3$ working blades, helix angle $\lambda \mathrm{s}=45^{\circ}$, and rack angle $\mathrm{\gamma}=8^{\circ}$ was used. The depth of cut was $a_{p}=15 \mathrm{~mm}$ including allowances between operations. The CNC program was developed using the CAD/CAM NX 8.5 software. The cutting speed for roughing and semifinishing operations was $v_{c}=300 \mathrm{~m} / \mathrm{min}$ and the feed per tooth of $0.08 \mathrm{~mm} /$ tooth in operations without feed change at the corners. After roughing $1 \mathrm{~mm}$ allowance was left. For samples in which the feed rate at the corners was reduced, a setting was applied that allowed gradual reduction of the tool feed rate to $50 \%$ in seven steps. The cutting speed for the finishing operation was $v_{c}=450 \mathrm{~m} / \mathrm{min}$, and the basic feed per tooth was $0.06 \mathrm{~mm} /$ tooth. After the semifinishing operation $0.15 \mathrm{~mm}$ allowance was left for the finishing machining.

The test stand used for the research was the Hwacheon Vesta 1000, 3-axis vertical milling center. This machine is equipped with a spindle motor with a maximum power of $18.5 / 15 \mathrm{~kW}$, with the possibility of obtaining the maximum speed of rotation equal to $12000 \mathrm{r} / \mathrm{min}$ which is important in machining aluminum alloys. It has a movable table of dimensions $1100 \times 500 \mathrm{~mm}$ and working range of X1000 x Y550 x Z500 mm.

The surface roughness measurements of the corners were carried out using the Hommel Tester T1000 contact profilometer. The profilometer has interchangeable measuring tips enabling linear measurement of holes, grooves, concave surfaces and convex surfaces. It enables measurement in sixteen different sizes of the measuring section from 0.48 to $16 \mathrm{~mm}$. It has two measuring ranges: $\pm 80 \mu \mathrm{m}$ in resolution $0,01 \mu \mathrm{m}$ and $\pm 320 \mu \mathrm{m}$ in resolution $0,04 \mu \mathrm{m}$.

\section{RESULTS AND DISCUSSION}

The results of surface roughness measurements are presented in the form of graphs. For each angle value, the average result from the three measurements was recorded. The graphs are compiled by the results of measurements of all types of machining with differentiation by the angle value of the corner.

The legend of the x-axis of Fig. 3 - 7: 
$\mathrm{R}$ - roughing; R SDC - roughing with feed deceleration in corners; SF - semi-finishing; SF SDC - semi-finishing with feed deceleration in corners; F - finishing; F SDC - finishing with feed deceleration in corners.

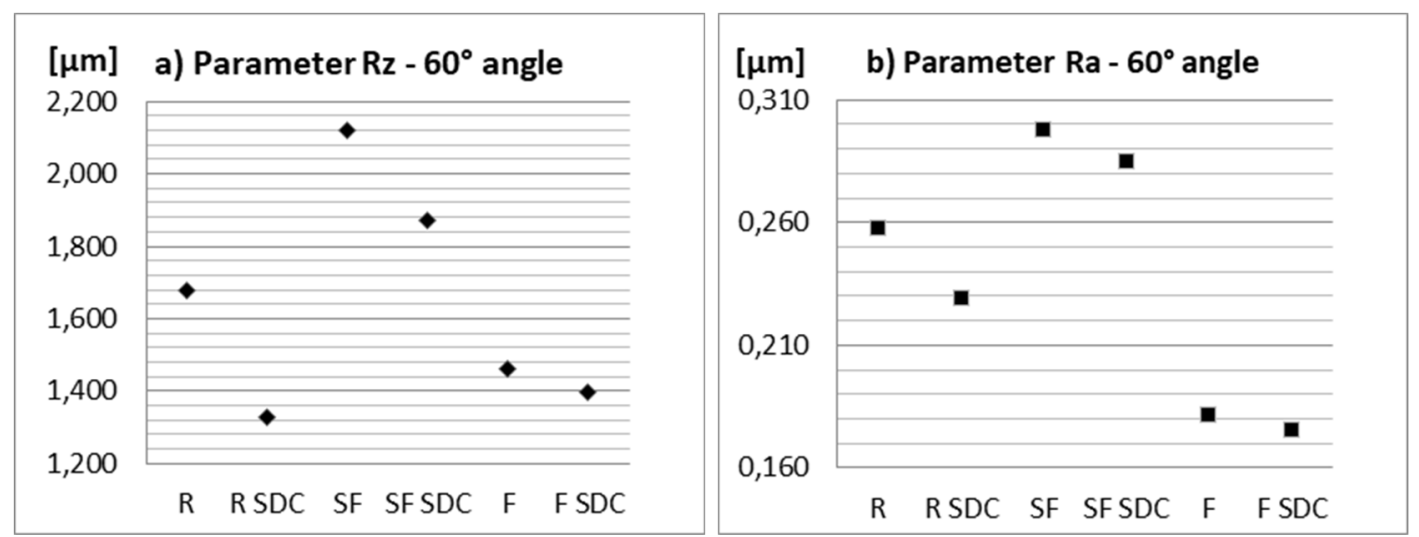

Fig. 3. Results of surface roughness parameters $\mathrm{Rz}-\mathrm{a}$ ), $\mathrm{Ra}-\mathrm{b}$ ) of $60^{\circ}$ corner angle sample

Analyzing the surface roughness measurement for a corner angle with a value of $60^{\circ}$ (Fig. 3), it can be seen that all measurements carried out with deceleration in the corners generate a lower roughness average - Ra, in relation to measurements carried out at a constant feed rate. For roughing and semi-finishing, it is approx. $20 \%$ less, and for finishing $-5 \%$ less. The average arithmetic roughness profile deviation for the measured surface of angle of $60^{\circ}$ corner also shows a similar relationship between the constant feed rate and machining with feed per tooth deceleration at the corners. However, these are lower percentages, i.e. approx. $11 \%$ less for roughing and approx. $5 \%$ less for the other two types of machining.
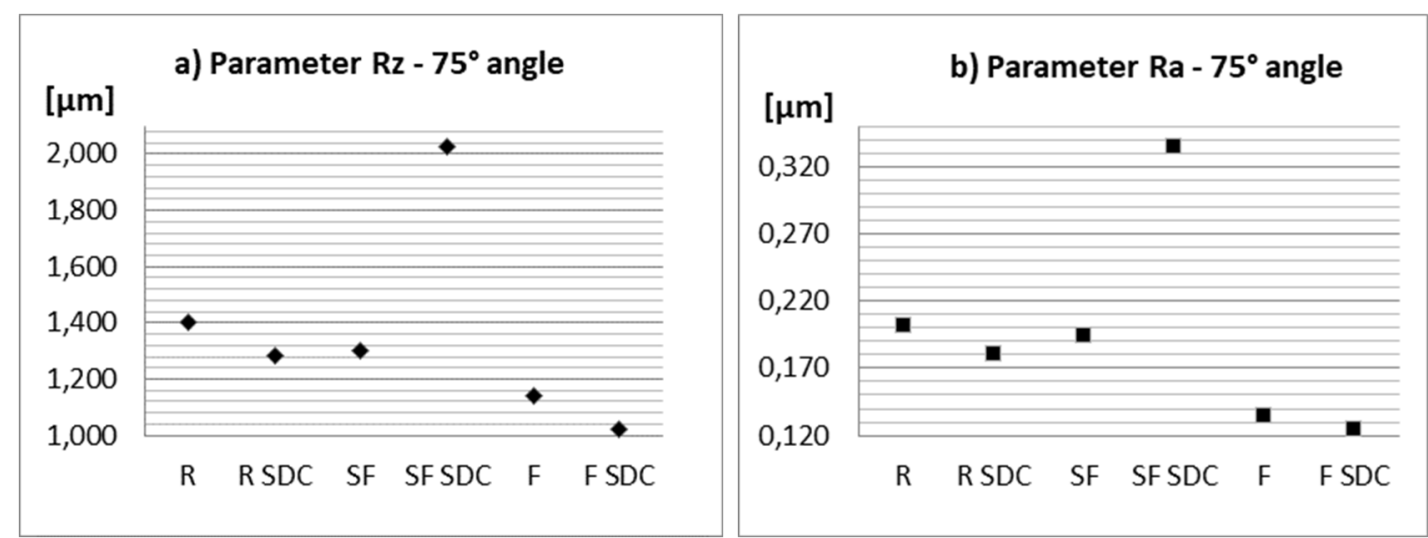

Fig. 4. Results of surface roughness parameters $\mathrm{Rz}-\mathrm{a}), \mathrm{Ra}-\mathrm{b}$ ) of $75^{\circ}$ corner angle sample

The same dependence can be observed on the majority of measured values of machined surfaces with feed deceleration in the corners and its lack. However, the percentages of the quality improvement of the measured parameter between the two treatment methods are different. In the case of an angle of $75^{\circ}$, it is approx. $10 \%$ lower value of the average roughness height in roughing and finishing (Fig. 4). The same applies to the parameter Ra. By performing subsequent types of operations on the samples tested, a better quality of the milled surface can be obtained. The anomaly is however, the semi-finished machining measurement, wherein was observed a more than $55 \%$ deterioration of the $\mathrm{Rz}$ parameter in the machining process with deceleration of feed rate in the corners and as much as $72 \%$ increase in the average arithmetic deviation of the surface roughness profile. After thoroughly viewing the mentioned corner in the sample, an obvious undercutting of the corner by an end mill can be noticed. 


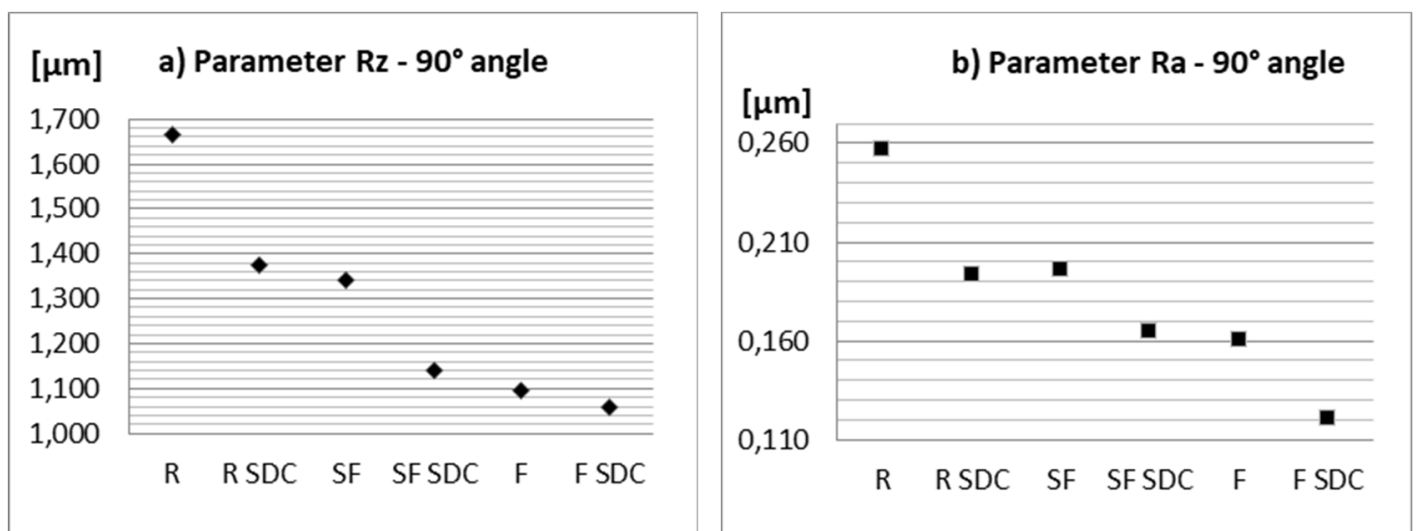

Fig. 5. Results of surface roughness parameters $R z-a)$, $R a-b)$ of $90^{\circ}$ corner angle sample

Analyzing surface measurements of the corner with an angle equal to $90^{\circ}$ (Fig. 5.) despite the dependence characteristic of almost all measurements, another recurrent relationship was noted. Focusing on values of $\mathrm{Rz}$ parameters achieved for particular types of machining, converge of result values achieved along with a more precise type of machining can be observed. Roughness measurement values for roughing are approx. 18\% lower for SDC machining. In semi-finishing, it is already about $15 \%$, and in the finishing process - less than $4 \%$. For $\mathrm{Ra}$, these differences are around $25 \%$ percent for roughing and finishing, and $15 \%$ in favor of the SDC for semi- finishing. In contrast, the difference between roughing with a constant feed speed and a finishing pass with feed deceleration in the corners generates almost $40 \%$ improvement in the surface quality obtained.
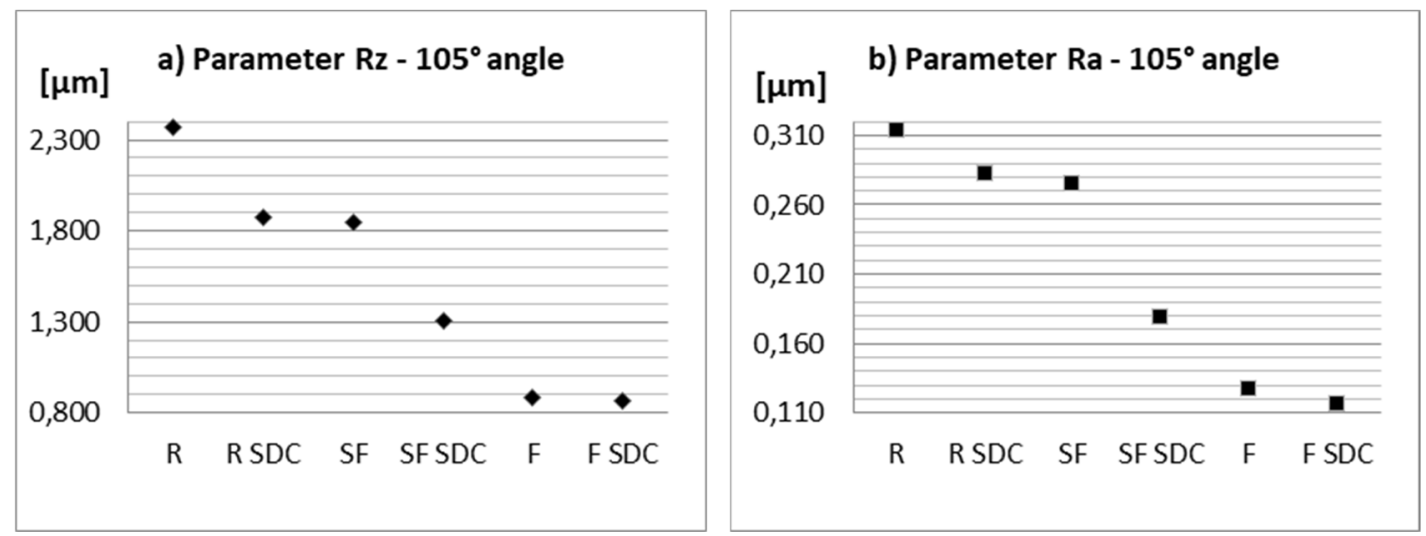

Fig. 6. Results of surface roughness parameters $\mathrm{Rz}-\mathrm{a}), \mathrm{Ra}-\mathrm{b}$ ) of $105^{\circ}$ corner angle sample

When measuring surface roughness of a sample with corner angle $105^{\circ}$ (Fig. 6) the decrease in measured $\mathrm{Rz}$ parameters is $20 \%$ for roughing, $10 \%$ for semi-finishing and only $2 \%$ for finishing passes. Above $60 \%$ increase in average roughness value is recorded between roughing and finishing. The average arithmetic deviation of the roughness profile shows the previously described characteristics, i.e. the reduction of the tested parameters, starting from roughing to finishing by $63 \%$. By separating it into individual types of machining, it gives a $10 \%$ improvement in roughing and finishing with feed deceleration in the corners and a $35 \%$ improvement for semi-finishing processing. 


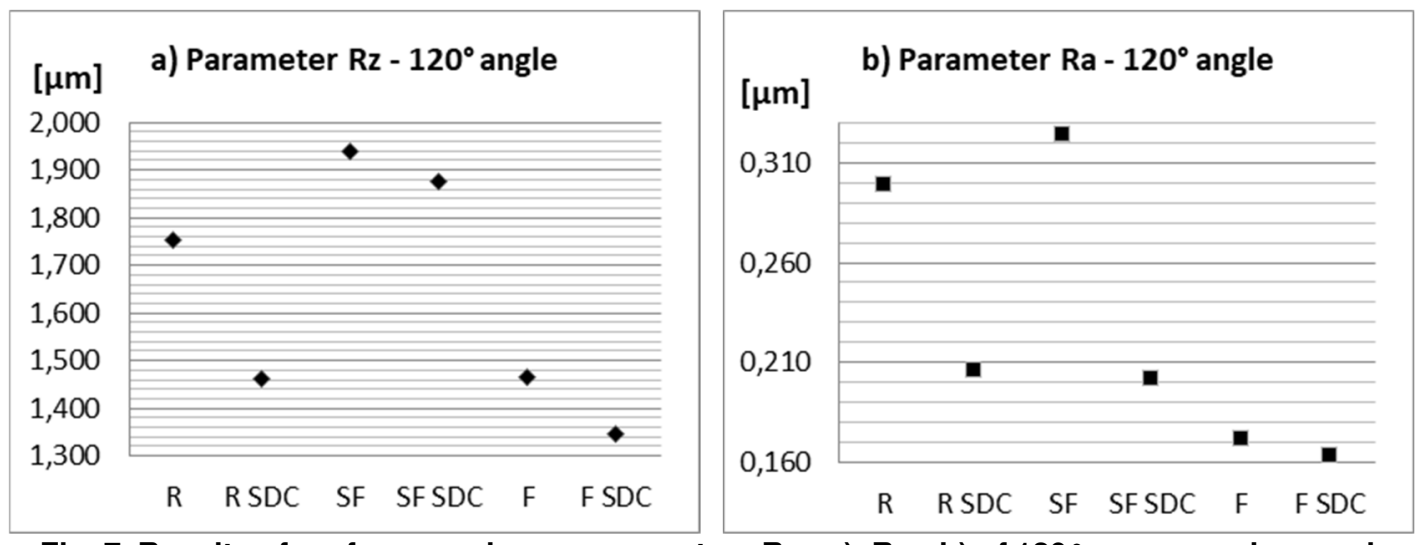

Fig. 7. Results of surface roughness parameters $R z-a)$, $R a-b)$ of $120^{\circ}$ corner angle sample

Based on measurements of the average maximum height of the profile - Rz surface of an obtuse angle of $120^{\circ}$ has been observed improvement of this parameter for SDC milling by $20 \%$ in rough machining (Fig. 7). Semi-finish treatment with the same criterion showed an improvement of the obtained result by less than $4 \%$, but in a general comparison to the implementation of rough machining, this is a worse result by approx. $10 \%$. This is due to drawing the tool towards the corner causing undercutting and deteriorating the quality of the surface. The parameter describing the arithmetic average of the absolute values of the profile heights over the evaluation length - Ra also shows large fluctuations between the operations at constant feed rate in the corner and variable feed by nearly $30-40 \%$, which confirms the visible traces of the undercutting of the test sample. The finishing treatment in both types of corner milling shows similar values of the Ra parameter, which at the same time are $90 \%$ smaller than those obtained in previous operation.

When comparing the results of roughing, it can be noticed that the measured acute angles show lower values of the $\mathrm{Rz}$ parameter in relation to the identical type of tests carried out at obtuse angles. Differences reach even $10 \%$. Almost twice as good surface quality was obtained in the corner at an angle of $75^{\circ} \mathrm{compared}$ to the worst result at $105^{\circ}$. Similarly for $\mathrm{Ra}$ parameter. The lowest values were recorded in the corner with an acute angle of $75^{\circ}$ and the highest in the corner with an obtuse angle of $105^{\circ}$. The entire measuring characteristic of all measured corners surfaces is quite irregular.

By analyzing the process of measurements for semi-finish machining, it is easy to see the reproducibility of the results for the values of the right angle. Both the Ra and Rz parameters reached the lowest value of the measurements carried out for the size of the mentioned corner angle. In spite of fairly different result values of all semi-finishing measurements, it is possible to notice significant reduction in the obtained values for both measured parameters.

In the finishing treatment, the differences between the obtained machining results with a constant as well as a variable feed rate are not as significant as in other types of machining. Results can be found within a maximum of $11 \%$ to less than $2 \%$ of the difference in the case of an obtuse angle of $105^{\circ}$. However, the values achieved between the different corners differ, reaching in the extreme case $40 \%$ difference. Referring to the Ra parameter, the differences between the two types of machining beyond the right angle range within $8 \%$. Also here, it is easy to notice a significant difference in the values achieved with $60^{\circ}$ and $105^{\circ}$ angle measurements.

\section{CONCLUSION}

As a result of the tests carried out, the assumptions formulated in the introduction of the article were verified. It can be said that there is an impact between the change of some technological parameters of the predetermined type of processing, and received quality parameters of machined samples. 
The following conclusions can be made on the basis of the research:

- There is a relationship between the size of the milled corner angle and the obtained surface roughness,

- The choice of the milling method with constant or variable feed per tooth within the corner has a direct influence on the obtained average surface roughness height,

- The size of the milled corner angle affects the accuracy of the part made.

Based on the results, the following conclusions for technologists' cadres in the processing of thin-walled pocket pieces can be formulated. It is recommended to reduce the speed of feed per tooth within the corners. Use machining divided into several types of operations, i.e.: roughing, semi - finishing and finishing. Program tool paths to obtain the smallest tool engagement angle. To do this, it is preferred to use tools with a radius smaller than the radius of the milled corner.

\section{REFERENCES}

Burek, J. and Płodzień, M. (2012). Wysokowydajna obróbka części ze stopów aluminium o złożonych kształtach. Mechanik, No 7, pp. 542-549.

Choy, H.S. and Chan, K.W. (2002). Machining tactics for interior corners of pockets. IJAMT, Volume 20(10), pp. 741-748

Jemielniak, K. (2004). Obróbka skrawaniem. Warsaw: Oficyna wydawnicza Politechniki Warszawskiej.

Kłonica, M., Kuczmaszewski, J., Matuszak, J., Pałka, T., Pieśko, P., Rusinek, R., Włodarczyk, M., Zagórski, I. and Zaleski, K. (2015). Obróbka skrawaniem stopów aluminium i magnezu. Lublin: Politechnika Lubelska.

Oczoś, K. E. and Kawalec, A. (2012). Kształtowanie metali lekkich. Warsaw: Wydawnictwo Naukowe PWN SA

Pieśko, P. (2014). Badania wpływu sztywności statycznej frezów trzpieniowych na dokładność geometryczną przedmiotów wykonanych ze stopów aluminium. Ph.D. Lublin University of Technology.

Pieśko, P. and Zagórski, I. (2011). Analiza porównawcza metod frezowania HSM, HPC oraz frezowania konwencjonalnego wysokokrzemowych stopów aluminium. Postępy nauki i techniki, No 7, pp. 219-226.

Tsui, K.S. and Chan, K.W. (2005). An efficient NC tool path planning approach. ICCIMA 2005: Sixth International Conference on Computational Intelligence and Multimedia Applications, Proceedings Pages: 132-137

Wei, Z., Wang, M.J. and Han, X.G. (2010). Cutting forces prediction in generalized pocket machining. IJAMT, No 50(5), pp. 449-458.

Yue, Caixu. Liu, Xianli. Ding, Yunpeng. Liang, S. (2018). Proceedings of the institution of mechanical engineers part b. Journal of engineering manufacture. Vol 232, no 7, pp. 1172-1181. 